\title{
Unengaged head at term in primigravida: does it affect the chance of having a normal delivery?
}

\author{
Sadiq Unnisa*, Poornima M. S.
}

Department of Obstetrics and Gynecology, Yenepoya Medical College Hospital, Mangalore, Karnataka, India

Received: 07 February 2019

Accepted: 06 March 2019

\section{*Correspondence:}

Dr. Sadiq Unnisa,

E-mail: drsadiqa12@gmail.com

Copyright: (C) the author(s), publisher and licensee Medip Academy. This is an open-access article distributed under the terms of the Creative Commons Attribution Non-Commercial License, which permits unrestricted non-commercial use, distribution, and reproduction in any medium, provided the original work is properly cited.

\begin{abstract}
Background: In Obstetrics it is traditional concept that fetal head engagement occurs by 38 weeks in primigravida. Unengaged head in primigravida has been considered a possible sign of cephalo pelvic disproportion. It is associated with higher risk of cervical dystocia, which has led to increased rate of caesarean section with its financial implication and future restriction of family size. Labour is prolonged, the duration of both latent and active phase increases, due to improper fitting high fetal head.

Methods: The prospective descriptive study was conducted at the Yenepoya Medical College hospital OBG Department. Study population included were 75 primi gravidas with unengaged head at term. Details of labour were noted down. Augmentation was done with oxytocin and dose of oxytocin was titrated . CTG was used to monitor fetal heart. Emergency LSCS was performed in patients with fetal distress or non-progress of labour. In case of vagina delivery, duration of 1st and 2nd stage, APGAR score at 1 and 5 minutes, and birth weights were recorded.

Results: Of the 75 primigravida $66.66 \%$ were in the age group of 21-25yrs. Majority of the women were of 39-40 weeks $(42.66 \%)$ of gestation. Common causes of unengaged head was deflexed head in 15 (20\%) CPD in 11 $(14.66 \%)$, loops of cord around neck in $8(10.66 \%)$, polyhydramnios in $2(2.66 \%)$, placenta previa type-I and II : anterior in $5(6.66 \%) 8$ patients were with occipito posterior position. No cause could be identified in 27 cases (36\%). Vaginal delivery occurred in $68 \%$ and LSCS in $32 \%$.

Conclusions: Unengaged head in primi gravida with spontaneous onset of labour is not an indication for LSCS. The attitude of watchful expectancy and timely intervention especially in those cases in which no significant etiological factor is found, the chances of vaginal birth increase there by reducing maternal land foetal morbidity.
\end{abstract}

Keywords: Foetal, Maternal, Outcome, Primigravida, Unengaged fetal head

\section{INTRODUCTION}

Labor is heralded when there is regular uterine contraction, followed by progressive cervical dilation, effacement and descent of the presenting part. ${ }^{1}$ In Obstetrics it is traditional concept that fetal head engagement occurs by 38 weeks in primigravida. This traditional concept does not correlate in clinical practice. In majority of primi engagement does occur before 38- 42week or even in first stage of labor. ${ }^{2}$ Unengaged head in primigravida has been considered a possible sign of cephalo pelvic disproportion (CPD). ${ }^{2-4}$ It is associated with higher risk of cervical dystocia, which has led to increased rate of caesarean section (CS) 5 with its financial implication and future restriction of family size. Labour is prolonged, the duration of both latent and active phase increases, due to improper fitting high fetal head. ${ }^{5}$ Prolonged labour exposes women to infection, 
ketosis obstruction, fetus for asphyxia, sepsis. ${ }^{5}$ Present study is conducted to determine the pregnancy outcome in primigravida with unengaged head at term. Aim is to determine the etiological factors in primigravida with high head at the onset of labor, duration of labor active intervention and feto maternal complications.

\section{METHODS}

The prospective descriptive study was conducted at the Yenepoya Medical College hospital Obstetrics and Gynaecology Department, Mangalore, India from February 2017 to September 2017. Study population included were 75 primi gravidas with unengaged head at term.

\section{Inclusion criteria}

- Term gestation (37-41wks)

- $\quad$ Single live fetus

- Vertex presentation

- No obvious CPD

- Intact membranes.

\section{Exclusion criteria}

- Multigravida

- Engaged head

- Non-Vertex

- Multiple gestation

- Gestational age less than 37 weeks/ greater than 41 weeks.

- Short stature

- Patient with obstetric complication like PIH, GDM.

The patients were admitted to labour theatre, demographic and history details were recorded. A thorough general, systemic and abdominal examination was done to confirm period of gestation, presenting part and fifth of fetal head palpable.

Per vaginal examination was done to note position, consistency, effacement, dilatation (in cms.), station, status of membranes and adequacy of pelvis. USG was performed in all the patients for fetal biometric parameters, EFW, AFI, placental location and its maturity.

Induction was done according to the predefined criteria in pts who did not spontaneously go into labour and details of labour were noted down. Partograph was used in all patients to assess the progress of labour. Augmentation was done with oxytocin where uterine contractions were not effective (to produce cervical dilatation and descent of the head) and dose of oxytocin was titrated as per requirement.

Cardiotocography was used to monitor fetal heart. Emergency LSCS was performed in patients with fetal distress or non-progress of labour. In case of vagina delivery, duration of $1^{\text {st }}$ and $2^{\text {nd }}$ stage, APGAR score at 1 and 5 minutes, birth weights, were recorded.

An informed consent was signed by all the patients to declare their agreement to be enrolled in the study, as agreed upon by the institutions ethical committee. The data was analysed using chi square test, fisher's exact test.

\section{RESULTS}

Of the 75 primigravida $66.66 \%$ were in the age group of 21-25 years (Table 1 ).

Table 1: Distribution of cases according to age.

\begin{tabular}{|l|l|l|}
\hline Age in years & Number & Percentage \\
\hline $18-20$ & 20 & 26.6 \\
\hline $21-25$ & 50 & 66.66 \\
\hline $26-30$ & 5 & 6.66 \\
\hline
\end{tabular}

Majority of the women were of 39-40 weeks (42.66\%) of gestation, followed by $37-39$ weeks (36\%) and 40-43 weeks $(22.33 \%)$ (Table 2).

Table 2: Distribution according to gestational age.

\begin{tabular}{|l|l|l|}
\hline Gestational age & No. of cases & Percentage \\
\hline $37-39$ & 27 & 36 \\
\hline $39-40$ & 32 & 42.66 \\
\hline $40-41$ & 16 & 21.33 \\
\hline Total & 75 & \\
\hline
\end{tabular}

Common causes of unengaged head was deflexed head in $15(20 \%)$ CPD in $11(14.66 \%)$, loops of cord around neck in $8(10.66 \%)$, polyhydramnios in $2(2.66 \%)$, placenta previa type-I and II anterior in $5(6.66 \%) 8$ patients were with occipito posterior position. No cause could be identified in 27 cases $(36 \%)$ (Table 3).

Table 3: Etiology factors.

\begin{tabular}{|c|c|c|}
\hline Etiology & $\begin{array}{l}\text { No. of } \\
\text { cases }\end{array}$ & Percentage \\
\hline Deflexed head & 15 & 20 \\
\hline CPD & 11 & 14.66 \\
\hline 2 loops of cord around neck & 7 & 9.33 \\
\hline 3 loops of cord around neck & 1 & 1.33 \\
\hline Polyhydramnios & 2 & 2.66 \\
\hline Placenta previa type 1,2 & 5 & 6.66 \\
\hline Occipitoposterior position & 8 & 10.66 \\
\hline No cause found & 27 & 36 \\
\hline
\end{tabular}

Among the 75 cases $45.33 \%$ had $4 / 5$ th of head palpable per abdomen, in $34.66 \%$ head of $3 / 5$ palpable and only $20 \%$ had free floating head. Spontaneous labour occurred in $32(42.67 \%)$ labour was either induced with Foley's 10 $(10.67 \%)$ and prostaglandin E2 gel in 35 (46.67\%) and 
augmentation was required in $80 \%$ of the cases (Table 4). Among them 48 (64\%) had vaginal delivery $3(4 \%)$ required vacuum assistance and rest $25(32 \%)$ underwent lower segment LSCS.

Table 4: Mode of delivery.

\begin{tabular}{|l|l|l|l|l|l|l|}
\hline & \multicolumn{9}{|c|}{ Augmentation } & No. of cases & Percentage \\
\hline Spontaneous & & 32 & $42.67 \%$ & & 80 \\
\hline \multirow{2}{*}{ Induction } & Foleys & 8 & & Required & 60 & 20 \\
\cline { 2 - 7 } & Prostaglandins & 35 & & Not required & 15 & 20 \\
\hline
\end{tabular}

Table 5: Distribution of cases according to fifth of fetal head palpable P/A and mode of delivery.

\begin{tabular}{|l|l|l|l|l|l|l|l|}
\hline Station & No. of cases & NVD & $\%$ & LSCS & $\%$ & Vacuum assisted delivery & $\%$ \\
\hline FF & 15 & 3 & 20 & 12 & 80 & & \\
\hline $4 / 5$ & 34 & 26 & 76.47 & 7 & 20.52 & 2 & 5.88 \\
\hline $3 / 5$ & 26 & 19 & 73.07 & 5 & 19.23 & 1 & 3.84 \\
\hline Total & 75 & 48 & 64 & 24 & 32 & 3 & 4 \\
\hline
\end{tabular}

Among 15 in FF head, $3(20 \%)$ had NVD and $12(80 \%)$ patient had LSCS. In 4/5 palpable head $26(76.47 \%)$ delivered normal, 7 (20.52\%) had LSCS and $2(5.88 \%)$ required vacuum assistance. In $3 / 5$ palpable head 19 $(73.07 \%)$ delivered vaginally, $5(19.23 \%)$ had to undergo LSCS and $1(3.84 \%)$ required vacuum assistance (Table $5)$. The different indication for LSCS was fetal distress $10(42.66 \%)$ arrest of descent $6(25 \%)$ arrest of dilation 3 $(12.5 \%)$ deep transverse arrest in $5(20.83 \%)$. Vaginal delivery occurred in $68 \%$ and LSCS in $32 \%$ (Table 5). Length of 1 st stage of labour ranged from $8 \mathrm{hrs}$. 30 minutes to $14 \mathrm{hrs}$. $30 \mathrm{~min}$. mean duration of $1 \mathrm{st}$ stage was 9 hrs. 45mins. Duration of 2nd stage of labour ranged from 30-110 mins. and the mean duration of 2nd stage was $35 \mathrm{~min}$. with regards to maternal outcome 2 patients had atonic PPH cervical tears in 4, 1 had perineal tear and 6 of them had wound infection. APGAR score at 5 mins.was between 7-10 in 64 cases $4-6$ in 9 case and $<3$ in 2 cases. 11 babies required NICU admission (Table 6). With the weight of the babies $47(62.67 \%)$ weighed between $3-3.5 \mathrm{~kg}$. $11(14.67 \%)$ weighed $>3.5 \mathrm{~kg} .13$ $(17.33 \%)$ weighed between $2.4-3.5 \mathrm{kgsand} 4(5.33 \%)$ were lessthan $2.5 \mathrm{~kg}$.

Table 6: APGAR score at 5 mins.

\begin{tabular}{|l|l|l|}
\hline A pgar at 5 min & No. of cases & Percentage \\
\hline $7-10$ & 64 & 85 \\
\hline $4-7$ & 9 & 12 \\
\hline$<3$ & 2 & 2.7 \\
\hline
\end{tabular}

12 babies had NICU admissions

\section{DISCUSSION}

Present prospective study was conducted on 75 primi gravidas with unengaged head at term. Aim was to analyze the cause, obstetrical outcome of labour with regards to duration, mode of delivery and fetal outcome.
The main factor for unengaged head identified were deflexed head, CPD, loops of cord around neck, Occipito posterior position, placenta previa and polyhydramnios. But in $36 \%$ of cases the cause could not be ascertained which was similar to study done by Shaik F et al. ${ }^{5-8}$

In the present study $65 \%$ delivered vaginally, $32 \%$ had LSCS and 4\% required vacuum assistance which was similar to Shahid Amallick et al (42\% ND and 39\% had LSCS). ${ }^{9}$ Ambawani2etal too had similar results. In the current study the mean duration of $1^{\text {st }}$ stage of labour was 9 hours. 45 mins and $2^{\text {nd }}$ stage of labour was 55 mins which was similar to studies by A Shrivastava10 et al and shaik F et al. ${ }^{5}$ Spontaneous labour occurred in (42.67\%) and rest required induction of labour followed by

Augmentation according to Saqib N study, a single important predictor for vaginal delivery in women with unengaged head was the natural onset of labour. ${ }^{11}$ In the present study mean birth weight was $2.83 \mathrm{kgs}$. Dayal $\mathrm{S}$ et al, Sunitha Sudhir et al reported mean birth weight of 2.77 and $2.83 \mathrm{kgs}^{12,13}$ Current study revealed APGAR score of 7-10 at 5 mins in 64 cases, 4-6 score in 9 cases and $<3$ in 2 cases which are similar to study by A. Shrivastava et al. ${ }^{10}$

\section{CONCLUSION}

Unengaged head in primi gravida with spontaneous onset of labour is not an indication for LSCS. The active medical and surgical intervention in case of floating head in primi at the onset of labour is very high.

The attitude of watchful expectancy and timely intervention specially in those cases in which no significant etiological factor is found, cases can be delivered vaginally with minimal maternal and fetal morbidity. 


\section{ACKNOWLEDGMENTS}

Authors would like to thank Ms. Geetha who assisted in technical aspects involving for the support during study.

Funding: No funding sources Conflict of interest: None declared

Ethical approval: The study was approved by the Institutional Ethics Committee

\section{REFERENCES}

1. Dwight JR, John ES. Normal labour, delivery, newborn care and puerperium. James RS, Ronald SG, Beth YK, Arthur FHD. Anforths obstetrics and gynecology. 9thed. Philadelphia: Lippincott Williams and Wilkins. 2003:53.

2. Ambwani B. Primigravidas with Floating Head at Term Or Onset Of Labor. The Internet Journal of Gynecology and Obstetrics. 2003.

3. Debby A, Rotmenseh S, Girtler O, Sadan O, Golan A,Glezerman M. Clinical significance of the floating head in nulliparous women in labour. J Reprod Med. 2003;48(1):37-40.

4. Yousuf R, Baloch SN. An audit of caesarean section. Park. J Med Res. 2006;45:28-31.

5. Shaikh F, Shaikh N. Outcome of primigravida with high head at term. J Pak Med Assoc. 2014;64(9):1012-4.

6. Mokasha FM .Comparison of pregnancy and labour in teen agers and primi gravida aged 21-25 years in Transkei. S Afr Med J. 1992;81(8):421-3.
7. Trevino TG, Puent GK. Indicationsfor caesarean section: Review of 300 cases. Ginecol Obstet Mex. 1998;66:411-3.

8. Shaikh F, Shaikh S, Shaikh N. Outcome of primigravida with high head at term. J Pak Med Assoc. 2014;64(9):1012-4.

9. Malik S, Asif U, Asif M. Primigravida; obstetrical outcome; with engaged versus unengaged fetal head with spontaneous onset of labour at term. Prof Med J. 2016;23(2).

10. A Shrivastava obstetrical outcomein primigravida with unengaged fetal head at spontaneous onset of labour at term gestation. IJSR 2017;6(8).

11. Saqib N, Saleem F, Saima R. Primigravidae with unengaged fetal head at term: an audit of delivery outcome. Ann King Edward Med Coll. 1999;5(2):177-9.

12. Dayal S, Dayal A, Outcome of labour in Nullipara at termwith unengaged vertex. Int $\mathrm{J}$ Med Res Rev.2014;2(2):130-13

13. Sudhir S, Mishra S., The outcome of labour in primigravida with term gestation and unengaged head at onset of labor-Indian J Obstet Gynecol Res. 2016;3(3):199-200.

Cite this article as: Unnisa $\mathrm{S}$, Poornima MS. Unengaged head at term in primigravida: does it affect the chance of having a normal delivery? Int $\mathbf{J}$ Reprod Contracept Obstet Gynecol 2019;8:1616-9. 